\title{
Corneal Suture Abscess Lead to Wound Dehiscence and Endophthalmitis after Vigorous Eye Rubbing: A Case Report
}

\author{
Majed Alkharashi $^{1^{*}}$, Amjad Fayez Alshehri ${ }^{2}$, Omar M. Alabbasi ${ }^{2}$, Rawan Nasser Althaqib ${ }^{3}$ \\ ${ }^{1}$ Department of Ophthalmology Department, King Saud University, Riyadh, KSA \\ ${ }^{2}$ King Khaled Eye Specialist Hospital, Riyadh, KSA \\ ${ }^{3}$ King Abdulaziz University Hospital, King Saud University, Riyadh, KSA
}

\begin{abstract}
Corneal sutures are commonly used in most ophthalmic procedures including Cataract surgery. Sometimes the suture becomes loose and exposed through the surface, which increases the risk of infection. Complications related to 10-0 nylon sutures, such as abscess, erosions, conjunctival inflammation, tarsal conjunctival ulceration, lid edema, and graft rejection, have been described very well in the context of corneal transplantation. However, remarkably little is published on infective keratitis secondary to corneal sutures after cataract surgery. Prompt well-timed observation and frequent monitoring are needed to prevent suture-related complications. Here, we are reporting an interesting case with a unique mechanism of a delayed onset suture related endophthalmitis following cataract surgery in a 38-year male due to probable wound dehiscence after vigorous eye rubbing.
\end{abstract}

Keywords: corneal Suture Abscess; Endophthalmitis; Eye Rubbing.

\section{Introduction}

Corneal sutures are commonly used in ophthalmic procedures and intraocular surgery including cataract surgery. When the suture become loose and erode through the surface, it might lead to infection. Bacteria can grow both as floating cells in a liquid environment (planktonic growth) and as adherent microcolonies that can evolve to form large biofilms at solid-liquid interfaces (sessile growth) [1]. Biofilm formation requires the adhesion of bacteria to a solid structure, followed by the bacterial production of polysaccharide glycocalyx (slime) that prevents antibiotics from gaining access to the microorganisms and reduces the efficacy of host defenses [1-3]. Biomedical devices (e.g. sutures) are among the solid surfaces that can be colonized by bacteria, with consequences that have been long underestimated, but can often be serious [4]. Complications related to 10-0 nylon sutures, such as abscess, erosions, conjunctival inflammation, tarsal conjunctival ulceration, lid edema, and graft rejection, have been described very well in the context of corneal trans- -plantation [5-8]. However, remarkably little is published on infective keratitis secondary to corneal sutures after cataract surgery $[5,6,9]$.

The purpose of this paper is to report a case with unique mechanism of a delayed onset suture related endophthalmitis following cataract surgery due to probable wound dehiscence after vigorous eye rubbing that gave a direct track to the pathogen to access the eye.

Corresponding Author: Majed Alkharashi Department of Ophthalmology Department, King Saud University, Riyadh, KSA Email: althaqib.r@gmail.com Received date: January 11, 2019; Accepted date: January 18, 2019; Published date: January 23, 2019

DOI: https://doi.org/10.31546/JJOAR.1002 


\section{Case report}

A 38-year-old male, known case of Diabetes mellitus Type II, Hypertension and Dyslipidemia. $\mathrm{He}$ underwent phacoemulsification with implantation of a Posterior Chamber Intraocular lens (Phaco Pc IOL) four months prior to the presentation and Pan Retinal Photocoagulation (PRP) for active Proliferative Diabetic Retinopathy (PDR) long time prior to the surgery. He presented to the emergency room complaining of redness, pain and drop of vision in the right eye over several hours after he rubbed his right eye aggressively post exposure to dust in a rural area. However, for three days prior to the presentation he had foreign body sensation, mild pain and redness, but he did not seek medical advice.

\section{Ocular examination upon presentation revealed:}

Right eye: light perception vision (in comparison to 20/30 vision on Snellen's chart post operatively).

Left eye: counting fingers 4 feet.

Intraocular pressure: normal both eyes.

Dim red reflex on the right eye.

Slit lamp examination of the right eye showed:

Mild lid swelling, severe conjunctival injection, cornea showed loose suture at the phacoemulsification main wound with apposed edges and small infiltrate $1.5^{*} 1.5 \mathrm{~mm}$ inferotemporal with small epithelial defect overlying it (without leak); Seidel's test negative.

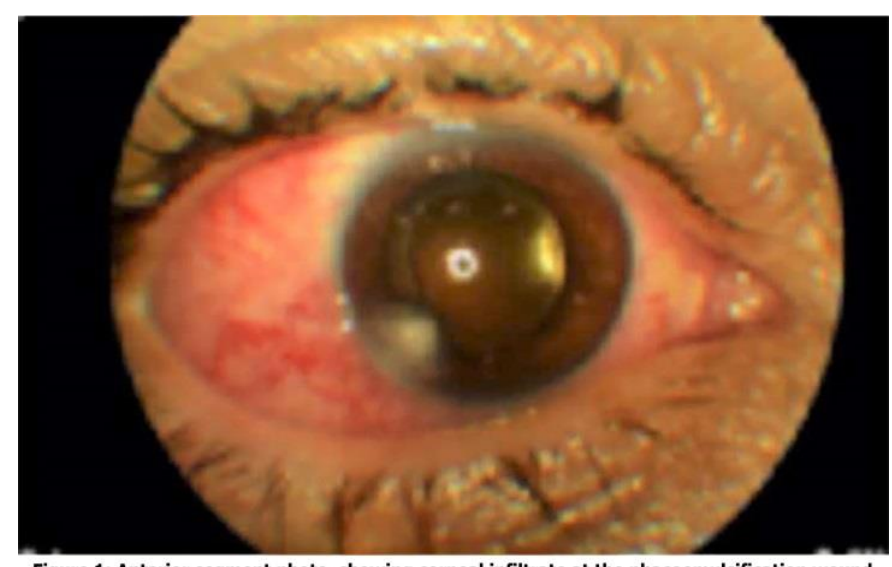

Figure 1: Anterior segment photo, showing corneal infiltrate at the phacoemulsification wound.

Anterior chamber was deep with 4+ cells with fibrinous reaction clogging the wound site. Pseudophakic.

Dim red reflex

No clear view to the fundus due to dense vitritis .
Ultrasound on presentation showed: Moderate Vitreous opacities with multiple membranes formation and shallow choroidal detachment.

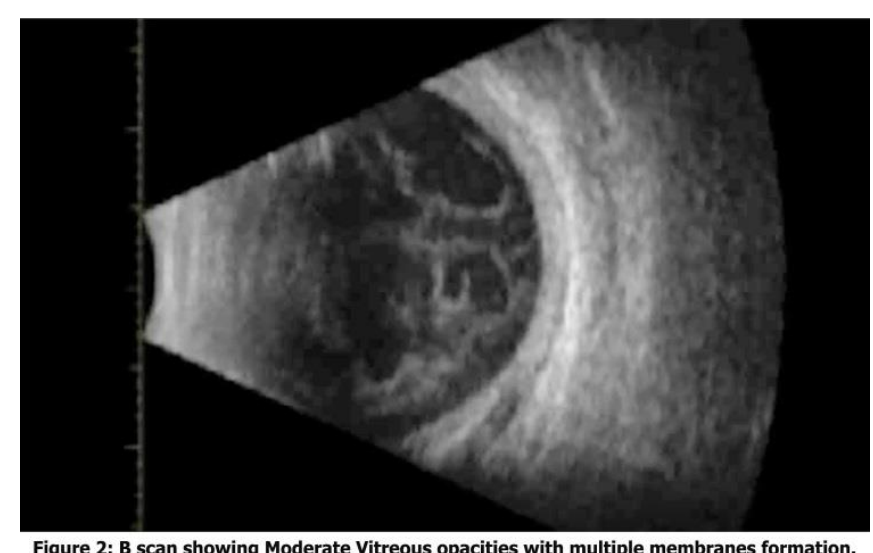

The patient was admitted as a case of endophthalmitis. $\mathrm{He}$ received intravitreal injection of Ceftazidime $(2.25 \mathrm{mg} / 0.1 \mathrm{ml})+$ Vancomycin $(1 \mathrm{mg} / 0.1 \mathrm{ml})+$ Dexamethasone $(0.4 \mathrm{mg} / 0.1 \mathrm{ml})$. in addition to topical Ceftazidime $(50 \mathrm{mg} / \mathrm{ml})$ every 1 hour+ Vancomycin (50 $\mathrm{mg} / \mathrm{ml}$ ) every 1 hour + Atropine three times a day to treat his corneal infiltrate.

During the hospital course, the patient was followed closely on a daily basis, to check his clinical response to the medical treatment. The culture from the suture and the infiltrate showed Methicillin Resistant Staphylococcus Aureus which was sensitive to Vancomycin. The topical antibiotics were tapered accordingly.

His vision in the affected eye improved to $20 / 200$ on snellen's chart over 1 week period. The conjunctiva quietens with a remaining sectoral injection inferotemporal toward the site of the wound, the infiltrate resolved with a remnant scarring. The anterior chamber was deep with 1+ cells mainly pigmented. Fundus examination showed improvement of the vitritis with residual localized vitreous strands and debris only, mainly temporally in a tract like pattern toward the phacoemulsification main wound, with clinically significant macular edema, flat retina with Pan Retinal Photocoagulation scars, and shallow choroidal detachment. 


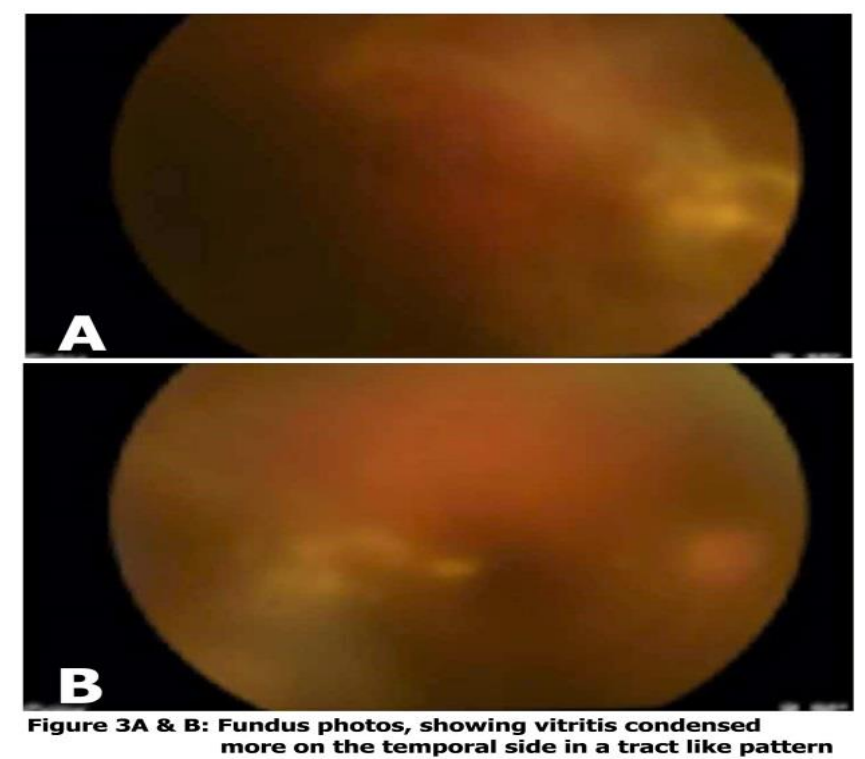

The patient was discharged on topical Vancomycin every 4 hours, Cyclopentolate every 8 hours and lubricants. Three weeks post discharge the patient was reevaluated in the clinic. The infiltrate resolved with remnant scarring, and the anterior chamber showed occasional cells. as a result, the vancomycin was discontinued. Moxifloxacin QID was started + Predforte as a tapering dose over 1 month + Cyclopentolate TID + Doxycycline 100mg PO once daily for 3 weeks. However, the vitreous strands and debris were still persistent temporally which bothered the patient visually. After 1 week the patient was seen in the retina clinic and planed for Pars Plana Vitrectomy+ endolaser + air fluid exchange due to the persistent vitreous opacities. A few months post vitrectomy, the patient returned with a vision of 20/30 OD with a very faint peripheral corneal scarring and clear vitreous.

\section{Discussion}

Few cases published in the literature on infective keratitis secondary to corneal sutures after cataract surgery $[5,6,9]$. Khurshid GS et al[10], reported five cases with bacterial keratitis secondary to corneal sutures after cataract surgery in which the infection progressed despite intensive topical antibiotics to endophthalmitis that required intravitreal antibiotics to control the infection. In these cases, the suture tract provided a route for bacteria to penetrate the eye [10].

It is difficult to determine if the sutures where full thickness or not, particularly when the stroma is not clear because of the keratitis [10].
However, our patient was not a straight forward case of delayed onset suture related endophthalmitis. Usually, this type of endophthalmitis occurs in full thickness suture bites where it has a direct contact with the anterior chamber or a disruption of the corneal epithelium (i.e., suture removal) [11].

The clinical scenario in our patient is suggestive of interestingly different mechanism of his endophthalmitis. The patient developed some mild pain and irritation for few days without any change in his vision and then afterward he rubbed his eye vigorously which lead to sudden painful visual loss over several hours, which made him eager to seek medical attention. His presentation was delayed cause he was living in a far area from any eye institution. The probable theory in his case that can explain the sequence of events, first he had a loose suture then he developed corneal abscess where the wound integrity weakened. But after the vigorous eye rubbing, dehiscence of the wound occurred.

Afterward the eye became hypotonus evident by the choroidal detachment on ultrasound. However, due to the delayed presentation probably the fibrinous material clogged the wound and the chamber had time to deepen and the pressure to build up. This sequence gave a direct track to the pathogen to access the eye.

Christopher RH et al [12] in their study, supports the fact that gram-positive bacteria account not only for the majority of cases of corneal suture-related infections but also corneal suture infection-related endophthalmitis[12].

Additionally, while Staphylococcus species seem to be more commonly isolated from degraded sutures, it appears that Streptococcus species are more often responsible for severe suture infections and endophthalmitis[12]. Similarly in our case the culture from the suture site and infiltrate showed Methicillin Resistant Staphylococcus Aureus (MRSA).

\section{Conclusion}

We recommend as the previous studies recommended removing the corneal sutures before discharging patients from survives. Full-thickness corneal sutures should be avoided. Patients with suture-related bacterial 
keratitis should be carefully reviewed for any signs of progression [10]. In addition to that, before suture removal patients should be instructed to seek medical attention if they feel foreign body sensation, pain or irritation as this could represent early symptoms of loose or exposed sutures [13].

\section{Conflict of Interest}

The authors have no conflicts of interest.

\section{References}

1. Stewart PS, Costerton JW. Antibiotic resistance of bacteria in biofilm. Lancet. 2000; 58:135-138.

2. Costerton JW, Stewart PS, Greenberg EP. Bacterial biofilm: a common cause of persistent infections. Science. 2001; 284:1318-1322.

3. Leid JG, Shirtliff ME, Costerton JW, Stoodley P. Human leukocytes adhere, penetrate, and respond to Staphylococcus aureus biofilms. Infect Immun. 2002; 70:6339-6345.

4. Nucci C, Artini M, Pasmore M, Missiroli F, Costerton JW, Selan L. A microbiological and confocal microscopy study documenting slime- producing Staphylococcus epidermidis isolated from a nylon corneal suture of a patient with antibiotic-resistant endophthalmitis. Graefe's Arch Clin Exp Ophthalmol. 2005; 243:951-954.

5.Christo CG, van Rooij J, Geerards AJM, Remeijer L, Beekhuis WH. Suture-related complications following keratoplasty: a 5-year retrospective study. Cornea. 2001; 20:816-819.
6. Tixier J, Bourcier T, Borderie V, Laroche L. Kératites infectieuses après kératoplastie transfixiante. J Fr Ophtal- mol.2001; 24:597-602.

7. Shahinian L, Brown SI. Postoperative complications with protruding monofilament sutures. Am J Ophthalmol. 1977; 83:546-548.

8. Leahey AB, Avery RL, Gottsch JD, Mallette RA, Stark WJ. Suture abscess after penetrating keratoplasty. Cornea. 1993; 12:489-492.

9. Huang SC, Wu SC, Wu WC, Hong HL. Microbial keratitis- A late complication of penetrating keratoplasty. Trans R Soc Trop Med Hyg. 2000; 94:315-317.

10. Khurshid GS, Fahy GT. Endophthalmitis secondary to corneal sutures: series of delayed-onset keratitis requiring intravitreal antibiotics. J Cataract Refract Surg. 2003; 29:1370-1372.

11. Gelender H. Bacterial Endophthalmitis Following Cutting of Sutures After Cataract Surgery. American Journal of Ophthalmology. 1982; 94(4), 528-533. doi: 10.1016/0002-9394(82)90249-5.

12. Christopher R Henry, Harry W Flynn Jr, Darlene Miller, Amy C Schefler, Richard K Forsterand, Eduardo C Alfonso. Delayed-onset endophthalmitis associated with corneal suture infections. Henry et al. Journal of Ophthalmic Inflammation and Infection. 2013; 3:51.

13. Lee BJ, Smith SD, Jeng BH. Suture-related corneal infections after clear corneal cataract surgery. Journal of Cataract \& Refractive Surgery. 2009; 35(5), 939-942. doi:10.1016/j.jcrs.2008.10.061 